ANNOTATION

\title{
COMFORT TO CONTORTION: THE LAST TEN YEARS OF ROWING
}

\author{
E. A. W. GREEN, BA, MEd, PGCertPE, ACP
}

Principal, Judgemeadow Community College, Leicester

Is it that Dr. Stallard's experience is a warning to rowing coaches that technological advances in rigging and boat construction have overtaken the physical capabilities of the individual, and, further is it time to take a new look at the land training programme?

Looking at the changes in the rig plan over the last decade or so, the oar has been lengthened and extended inboard by $1 \frac{1}{2}$ inches, the rigger extended $2 "$, the gate/fulcrum moved forward 1 " and the slide extended by $6^{\prime \prime}$ or more. To maintain the oar at a $45^{\circ}$ catch to the boat with full body compression has reduced the forward lean from the hips by $60 \%$, or the need to twist from the anterior axis by $50 \%$. This in itself looked at in isolation should reduce the likelihood of backstrain.

However, to incorporate the extended slide forward in the same boatspace has necessitated the lifting of the feet, at the least to avoid cutting the calf muscle when the legs are 'straightened' and supposedly to increase the drive of the legs through the work. At full

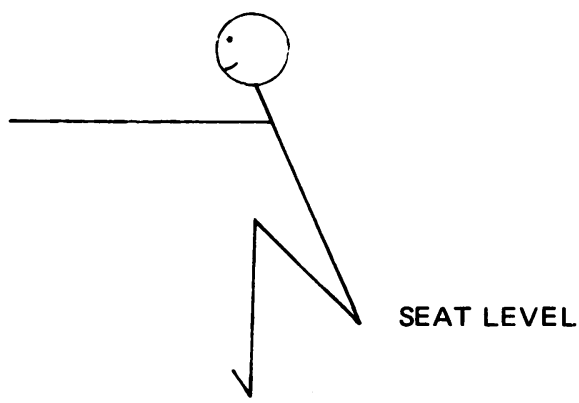

Fig. 1. Traditional rig body position.

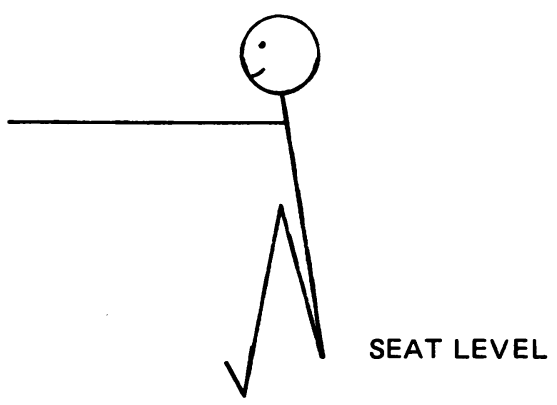

Fig. 2. Modern rig body position. compression, therefore, is not the flexibility of the spifie now increasingly inhibited even with flexible shoes, $\overrightarrow{a s}$ opposed to the original clogs, fitted. (The heels were originally fixed at $7 \frac{1}{2}$ inches below the seat.) Here $\mathscr{C}_{\mathrm{s}}$ possibly the danger point in the adjustment in the boat since there is allowance for the ball of the foot to Ge raised to the level of the seat and even higher. (This could possibly impose a downward drive on the boat $3 t$ the initiation of the stroke.)

Weight training outside the boat has increased cofisiderably, possibly without enough regard to the flexibility of the body needed. Is the "contralateral situp" with the feet flat on the floor enough to emulafe the new catch position?

It should be of some concern that advanced equipment is freely used by club oarsmen and coaches w may be tempted to use the extremes of rig in the hore of emulating the international success of the A.R.尺. squad without the knowledge/experience to realise the physical damage they may be doing unto themselves aæd those in their charge.

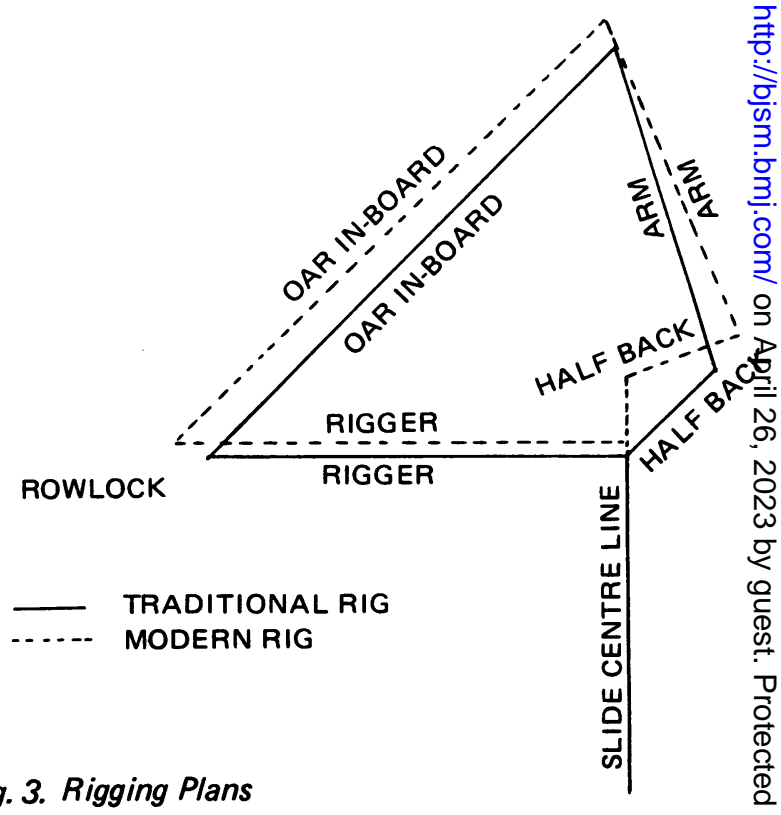

Fig. 3. Rigging Plans

Note: Moo'ern style lifts shoulders: with thigh/truak compressed possible need of cross-lateral twist to reafech oar at $45^{\circ}$ to boat 